\title{
Mapping creative pedagogies in open wiki learning environments
}

\author{
Mario Barajas ${ }^{1}$ - Frédérique Frossard ${ }^{1}$
}

Received: 19 July 2017 / Accepted: 14 November 2017

(C) Springer Science+Business Media, LLC, part of Springer Nature 2017

\begin{abstract}
As applied to education, creativity has become an increasingly common, yet often unattainable learning objective. Educators need innovative approaches and tools to effectively apply creative teaching practices. The present study aims to investigate how wiki methodologies can foster creative pedagogies. Wikis constitute a good candidate for stimulating creative teaching approaches. Indeed, they provide flexible and open environments which foster collaboration and students' active participation. However, a gap remains in the literature regarding the relationship between wikis and creative pedagogies. In addition, the use of wikis by teachers and students as collaborative editing tools in today's classroom has been scarcely studied. In this multiple case study, seven school teachers from different educational centres designed four scenarios mediated by wikis and applied them with 143 students. Using in-depth interviews and expert evaluations, we explored how creativity emerges while teaching and learning with wikis. Based on results, we propose a map of creative pedagogies that appeared as the most prominent in the context of wiki-based learning, together with their characteristic components. Namely, the emerging creative pedagogies are synergistic collaboration, learner-centred, knowledge connection and open-ended ethos. This mapping can be applied to different educational contexts, although it may vary according to the specificities of the methodology and technology used. The study raises discussion on the pedagogical possibilities offered by the participative digital culture that defines wiki approaches.
\end{abstract}

Keywords Wiki-based learning - Creative education · Creative pedagogies · Collaborative learning $\cdot$ Multiple case study

Mario Barajas

mbarajas@ub.edu

1 Facultat d'Educació, Universitat de Barcelona, Passeig Vall Hebrón, 171, 08035 Barcelona, Spain 


\section{Introduction}

Creativity is essential for negotiating the uncertainties and innovations in the modern society (Beghetto and Kaufman 2014; Lin 2014). In this context, developing creative skills has become a central objective in educational policies worldwide (NACCCE 1999). The research community acknowledges that creativity can be taught (Amabile 1996; Craft 2001; Lin 2011), even though creative teaching practices are often hindered by institutional constraints such as overloaded curricula and standardized evaluation procedures (Cremin and Barnes 2014). Furthermore, there are no tangible guidelines for helping teachers to adopt strategies that may nurture their students' creativity (Lin 2011). In order to integrate creativity in teaching practices, we need to provide teachers with concrete approaches and tools.

Wikis constitute a good candidate for stimulating creative teaching approaches. Indeed, they provide flexible and open environments which foster collaboration (Duffy and Bruns 2006) and students' active participation in the production of content (Parker and Chao 2007). However, there remains a clear gap in the literature regarding the potential of wikis to promote creativity in education, and further investigation is needed. In addition, the use of wikis by teachers and students as collaborative editing tools in today's classroom has been scarcely studied (Judd et al. 2010). The present study seeks to provide new insights for integrating creativity in teaching and learning settings. To do so, it investigates how wiki-based learning can foster creative pedagogies.

What kind of creativity appears, and how do creative pedagogies emerge in the creation and application of wiki-based learning scenarios? In order to understand the relation between wiki-based learning and creativity, the study seeks to identify and characterise the creative pedagogies that emerge when teachers design and use wiki environments. To provide a rich description of creativity complex dynamics, we needed to closely approach teachers, gather their subjective perspectives and get an intimate picture of their specific experience. In the context of the WikiSkills project, ${ }^{1}$ we organized a multiple case study in which seven teachers from two different educational levels (primary, secondary) and one other educational sector (adult education) designed and applied wiki-based learning scenarios with 143 students in four educational centres. The study maps the components of creative pedagogies at stake during the design and application of wiki-based learning scenarios.

\section{Theoretical background}

\subsection{Creative education}

Definitions of creativity generally focus on imaginative, novel outcomes that are purposeful or valuable. There is a consensus that creativity involves posing new

\footnotetext{
${ }^{1}$ European Union, Lifelong Learning Program, Key Activity 3 Information and Communication Technologies, http://www.wikiskills.net
} 
questions, generating a wide spectrum of ideas and reflecting on problemsolving processes (Craft et al. 2014b). As applied to education, the creativity phenomenon is regarded as a developmental construct and lifelong process which teaching is amenable to (Amabile 1996; Lin 2011). Current research suggests clear directions regarding methods of integrating creativity in education, holding that: (1) it should be part of an inclusive approach which considers that all individuals can be creative (NACCCE 1999); (2) it should focus on everyday creativity, also known as little-c (Craft 2001) and mini-c (Beghetto and Kaufman 2014), which gives more importance to students' personal processes and subjective self-discoveries than to their outstanding accomplishments (Big-C); and (3) it should be accompanied by a domain-wide approach which considers that creativity can be developed in all school subjects (Craft et al. 2014a). In addition, some important authors in the field (Beghetto 2010; Sawyer 2012) consider teachers as key-players for bringing creative practices into education.

More specifically, the literature on creativity in education distinguishes between two foci (Craft 2005; Jeffrey and Craft 2004; NACCCE 1999; Lin 2011): teaching creatively (in the words of the NACCCE report, "using imaginative approaches to make learning more interesting and effective", p. 89) and teaching for creativity (focusing on students' creative abilities). As observed by several authors (Craft et al. 2014b; Lin 2011, 2014), these approaches not only run parallel, but are interconnected. Our study therefore integrates both, addressing creative pedagogies as teaching practices which foster students' creativity.

The literature identifies a wide range of creative pedagogies. In a systematic review, Davies et al. (2013) points out the flexible use of space and time, the provision of elements of novelty and the use of the outdoor environment. The authors also highlight mutual respect, dialogue, and negotiation between teachers and students, as well as the participation of educators as learners in the classroom activities. In a model of creative pedagogies applied to game-based learning, Frossard et al. (2015) emphasize approaches which connect to students' life and interests (to make learning meaningful and engaging), create a bridge between different disciplines (to facilitate the interrelation across domains and place knowledge in a wider context), propose flexible evaluation strategies (which value student progress and provide tools for reflection), and enhance self-learning (i.e., encouraging student ownership, autonomy, and active participation in the production of meaning). Other research has also affirmed and developed the importance of self-learning; for example, Cremin and Barnes (2014) highlight the importance of adopting an agency oriented ethos to develop students' self-management skills. The authors also consider employing multimodal teaching approaches and switching between modes and sources, making space for exploration and discovery, as well as modelling risk taking, by tolerating ambiguity, leaving space for uncertainty, and providing safe, non-judgmental environments. In this sense, students are offered the possibility to try before getting it right, and use failure as positive (Sawyer 2012). Creative pedagogies also encourage exchanges, solidarity, and cooperative learning methods (Craft 2005); Sawyer (2012) draws special attention to collaborative and improvisational practices in ways that help students externalize their understandings and foster metacognition. 


\subsection{Wiki-based learning}

Wiki environments are hypertext systems that allow users to consult, link, and create web pages, as well as to reorganize structure and content (Leuf and Cunningham 2001). Their inherent affordances (multiuser edition, content development tracking, version management, asynchronous written communication) naturally support collaborative processes (Cole 2009; Ng 2016).

When applied to educational contexts, wikis can promote many characteristics of creative pedagogies: they offer flexible and open learning environments (Duffy and Bruns 2006), as well as enhance students' autonomy and reflective learning through their active participation and construction of meaning in the production of content; furthermore, their collaborative nature allows for peer interaction and group work, thus facilitating knowledge sharing and building (Parker and Chao 2007).

Wikis have demonstrated their usefulness in supporting a wide range of pedagogical activities, including collaborative writing, literature review, group discussion, project planning, problem solving, creation of knowledge repositories, and contribution to public wikis (Duffy and Bruns 2006; Parker and Chao 2007). Various studies report their successful application in primary and secondary education (Pifarré and KleineStaarman 2011; Pifarré et al. 2014), higher education (Popescu 2014), and teacher education (Biasutti and El-Deghaidy 2012).

On the other hand, several studies highlight challenges to the successful use of wikis in the classroom. These include technical constraints (Cole 2009), students' fear of showing draft work to others and concern about plagiarism (Su and Beaumont 2010), and the increase in teachers' workload when assessing collaborative processes (Kear et al. 2014). In addition, some authors report that wikis do not automatically encourage collaborative learning: for example, Hadjerrouit (2012) points out students' tendency to cooperate (divide labour among themselves and work separately) rather than collaborate (coordinate efforts to accomplish a task collectively). Finally, wiki-based learning methodologies challenge the traditional concept of construction of formal academic knowledge, which is featured by hierarchic, authorial, individual views (Ricaurte-Quijano and Carli-Álvarez 2016); instead, wikis promote an innovative model of knowledge production, based on free culture, peer production, and open learning, which results in the creation of collective intelligence. It appears challenging to integrate this change of paradigm in formal learning settings. Hence, beyond technical usability, the successful implementation of wikis hinges upon teachers and students establishing clear guidelines on social and cultural practices related to collaborative working and open learning (Popescu 2014; Judd et al. 2010). In addition, there remains a gap in the literature regarding the relationship between wiki environments and creative education. Although some authors have explored how wikis can support collaborative creativity (Pifarré et al. 2014), there are few studies on their potential to foster creative pedagogies.

To sum up, this theoretical background highlights three main challenges: (a) teachers need to be provided with concrete pedagogical approaches that support creative pedagogies; (b) the barriers to collaborative learning processes mediated by wikis need to be addressed; and (c) the current gap in the literature between wiki approaches and creative pedagogies needs to be bridged. 


\section{Research goal and methodological design}

As a problem statement, the present research tackles the need for teachers to have innovative approaches and tools to effectively apply creative teaching practices. In the light of the theoretical background, we aimed to analyse the potential of wiki-based learning environments to foster creative pedagogies. We designed a research project in which teachers created and implemented their own wiki-based learning scenarios. The following question guided our study: how do creative pedagogies emerge in the creation and application of wiki-based learning scenarios?

\subsection{Methodological design}

Our qualitative approach adopted a multiple case study strategy. This allowed us to address different educational contexts and provided a rich description of the complex dynamics of creativity. We could address teachers' and students' perspectives, examining their activities in natural settings and, drawing an intimate picture of their experience using wiki approaches.

In the context of the research, we organized an open call to invite Spanish teachers to enroll in a training course on the educational use of wikis. We trained participants in relation to technical, collaborative, and pedagogical aspects of wikis, as well as to the main concepts and tools around open digital environments and open learning. Furthermore, we guided teachers in the design of their wiki-based learning scenarios: they defined their teaching context (i.e., students' characteristics, discipline taught, and teaching objectives); organized and sequenced wiki-based learning activities; and, planned evaluation strategies and required resources (e.g. learning content, materials, technologies and equipment). Afterwards, we followed up teachers during the application of scenarios with their students. All along this process, we were able to develop a trusting relationship with them.

\subsection{Selection of cases}

From all scenarios designed by teachers, we selected four, each one constituting a case, using a purposeful sampling process (Creswell 2012): (a) critical sampling (scenarios of teachers who were interested in introducing wikis in their class); (b) finalization of the scenarios (some teachers could not finalize their scenarios); and (c) maximal variation sampling (scenarios tackling different disciplines, levels, centres and scenario types). Hence, our unit of analysis comprised four scenarios implemented in different Spanish educational centres (one primary school class, two secondary school classes from different schools, and one language school class) with seven teachers and 143 students.

In Case 1, four secondary school teachers from different disciplines co-designed a cross-curricular scenario, involving students in different collaborative writing activities in a common wiki environment: reading of the novel Little Red Riding Hood in Manhattan $^{2}$ and written expression around the book topics (Spanish literature); research on the United Nations headquarters, organization and roles, and elaboration of a letter

\footnotetext{
$\overline{{ }^{2} \text { Written by Carmen Martín Gaite, }} 1990$
} 
to their leaders (social sciences); thematic study of the song "Empire State of Mind"3 (English as a foreign language); description of Manhattan museums and artworks (visual arts). During one trimester, teachers implemented the scenario with 61 students aged 13-14.

In Case 2, a secondary school teacher designed and implemented a scenario involving students in creating a knowledge repository: during 9 sessions, 23 students (age 15-16) co-created two wiki-based encyclopaedias, one on non-metallic materials and one on pneumatic elements. They elaborated definitions, classifications, characteristics, and applications in the real world. ${ }^{4}$

In Case 3, an English teacher created and applied a collaborative writing scenario in which 40 adult students used a wiki environment to imagine and elaborate the end of a fairy-tale, reflecting on the best ways to express their ideas and correcting each other's contributions.

As for Case 4, a primary school teacher designed and applied a scenario in which she involved 22 students (age 7-8) in wiki-based written expression and communication activities (e.g. storytelling, word challenges, song writing).

Table 1 summarizes the particularities of each case.

\subsection{Data collection and analysis}

To approach the phenomenon of creativity from different perspectives and ensure the credibility of the research, we gathered data from different sources (interviews, observations and documents) and individuals (teachers, students, and an expert in wikis and education).

First, we conducted semi-structured interviews with each of the seven teachers to explore their subjective perceptions regarding the following topics: teaching methodologies employed, emerging creative pedagogies, opportunities and challenges encountered, and students' skills development. The interview guide (see Appendix) was developed around these topics, reviewed by an expert in wikis and education (a member of the educational team of the Wikimedia movement affiliate: the Catalan chapter Amical Wikimedia), and accordingly adapted. Examples of interview questions were "How did you organize educational activities around the wiki?", "What skills did students develop while working with wikis?" and "What challenges did you encounter while designing and applying your wiki-based learning scenario?" For all cases, interviews were conducted face-to-face and tape-recorded.

Second, an expert evaluation of each of the four scenarios was carried out following a common protocol and grid: the afore mentioned expert analysed the learning scenario and the related wiki environment according to a set of criteria on creative pedagogies (e.g., the link between different knowledge domains, connection to students' profile, collaboration opportunities), and produced a feedback report.

Additionally, in Case 1, we conducted one focus group interview (video-recorded) with 12 students, addressing their experiences while learning with wikis.

Table 2 summarizes the data collection instruments and specifies the codes used for analysis.

\footnotetext{
${ }^{3}$ Performed by Jay-Z and Alicia Keys, 2009

${ }^{4}$ Access to the wiki activity: www.trinitariasbarcelona.es/mediawiki
} 


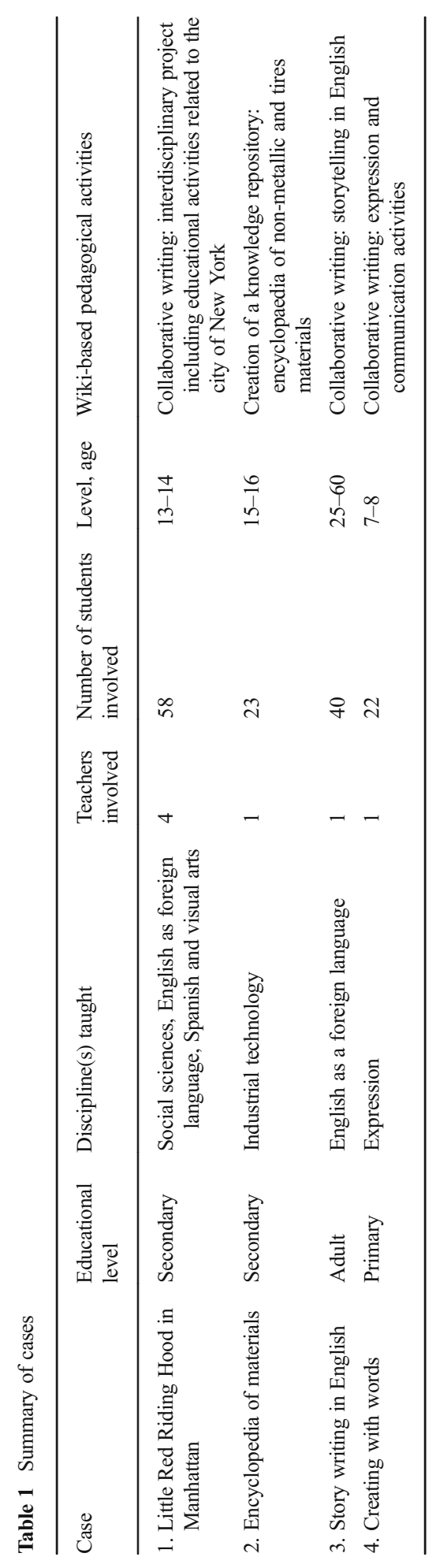


Table 2 Overview of the data collection process and coding system

\begin{tabular}{lccc}
\hline Case 1 (code: C1) & Case 2 (code: C2) & Case 3 (code: C3) & Case 4 (code: C4) \\
\hline $\begin{array}{c}4 \text { teacher interviews } \\
\text { (code: IN-C1) }\end{array}$ & $\begin{array}{c}\text { 1 teacher interview } \\
\text { (code: IN-C2) }\end{array}$ & $\begin{array}{c}\text { 1 teacher interview } \\
\text { (code: IN-C3) }\end{array}$ & $\begin{array}{c}1 \text { teacher interview } \\
\text { (code: IN-C4) }\end{array}$ \\
$\begin{array}{c}\text { 1 expert evaluation } \\
\text { (code: EE-C1) }\end{array}$ & $\begin{array}{c}\text { (expert evaluation } \\
\text { (code: EE-C2) }\end{array}$ & $\begin{array}{c}1 \text { expert evaluation } \\
\text { (code: EE-C3) }\end{array}$ & $\begin{array}{c}1 \text { expert evaluation } \\
\text { (code: EE-C4) }\end{array}$ \\
$\begin{array}{c}\text { focus group with 12 } \\
\text { students (code: FG-C1) }\end{array}$ & - & - & - \\
\hline
\end{tabular}

We first conducted a preliminary exploratory analysis (Creswell 2012) by repeatedly scanning data in order to understand them in general terms, as well as to create first ideas and concepts. Afterwards, we performed a thematic data analysis, highlighting patterns of meaning and ultimately identifying the most important themes. Coding was carried out through a within-case analysis, followed by a comparative analysis, in order to identify common and different themes among all four cases. Hand analysis was preferred in order to keep close to the data and to have a hands-on feel for it, by manually sorting, organizing, and locating words in the text (Creswell 2012).

\section{Results}

This section describes how creative pedagogies (i.e., teaching strategies which foster students' creativity) emerged during the design and application of wiki-based learning scenarios. Following the comparative analysis performed among the different cases, we were able to highlight four primary themes as creative pedagogies, namely (a) synergistic collaboration, (b) learner-centred, (c) knowledge connections, and (d) open-ended ethos.

\section{a. Synergistic collaboration}

In all cases, the affordances of wiki environments facilitated expression, dialogue, and information sharing. Using the collaborative edition and discussion functionalities, all students could express their opinions and share their perspectives (IN-C1, IN-C2, IN$\mathrm{C} 3$, IN-C4). One teacher remarked on his surprise at being able to "establish a dialogue about arts, with all students expressing and participating, although it was a big group" (IN-C1). Furthermore, students could easily organize their work by communicating and commenting on content, as well as by working on shared tasks and exchanging resources simultaneously, both at school and at home (IN-C1, IN-C3, FG-C1). Teachers could monitor students by interacting through the different wiki functionalities.

Wikis allowed for efficient cooperation among students through an efficient division of assignments into tasks and a fair distribution of tasks. In $\mathrm{C} 1, \mathrm{C} 2$ and $\mathrm{C} 3$, teachers established a set of fundamental principles for organizing the wiki activities, which students used to draw up their own rules: they identified group objectives and built their own work plan by defining and distributing a series of tasks that included supervising, collecting information, summarizing, and communicating with the teacher (IN-C1, IN-C2, IN-C3). Through collaborative edition, students could easily complete their respective tasks. 
Beyond cooperation, wiki environments appeared to inherently facilitate collaborative writing practices among students. They proved to "naturally monitor the co-writing process" (EE-C3) from drafting to proofreading, allowing students to write, evaluate each other's contributions (IN-C1, IN-C2,IN-C3), comment, negotiate content (IN-C3), and reflect on how to improve texts and correct mistakes (IN-C1, IN-C2,IN-C3).

Throughout the wiki activities, teachers and students encountered doubts about technical aspects (e.g., choosing the best wiki platform and, solving problems related to simultaneous edition) and often discussed the "best way of organizing educational activities" (IN-C2) such as group assignments and the distribution of activities at school and at home. Furthermore, students often knew as much as teachers did about the environment $(\mathrm{C} 1, \mathrm{C} 2)$. Together, they progressively discovered how to make the best use of wikis' pedagogical affordances. When facing obstacles and doubts, they investigated and reflected together to find adequate solutions (IN-C1, IN-C2, IN-C3). In the words of one teacher, "I still smile when I remember this project because as teachers and students we understood one another; because we, the teachers, actually had to come up to scratch with the kids" (IN-C1).

The transparency of wiki environments (afforded by multiuser edition, content development tracking, and version management) allowed for democratic and fair-minded classroom practices: students could equally distribute tasks (IN$\mathrm{C} 1$, IN-C2, FG-C1) and actively contribute to the completion of their assignments (EE-C1, EE-C2, EE-C3). At any time, they could access the tasks and actions taken by their classmates; furthermore, teachers could appreciate students' real work by making sure that they were given "the same rights and opportunities" (IN-C1). Students positively valued this equitable working style (FG-C1): "normally, we have to work on our own, or some people work more than others; but if we do it this way, using wikis, we can make sure that everybody works in an equal way, and this is better".

In all cases, working with wikis appeared to promote readiness to read, analyse, respect, and evaluate classmates" "different opinions and ways of working" (IN-C1) and also "integrate them [the differences] into a common work" (IN-C3). Secondary school students were initially reluctant to integrate their classmates' content into their own work and reach consensual decisions. As a teacher puts it, "they were used to working in an individual manner, and were generally uncomfortable with teamwork" (IN-C1). As they worked through the activities and used teachers' guidance, however, they progressively learnt to negotiate content and reach consensual decisions when there were conflicts of opinion (IN-C1, IN-C2).

As observed above, secondary school students initially resisted teamwork. They tended to focus on their individual objectives and sometimes displayed competitive attitudes, thinking that their grades might be influenced by others (IN-C1, IN-C2). Little by little, however, they learnt to prioritize the group objective, as their grades depended on the team's achievement (IN-C1, IN-C2); they understood that the responsibility lays with the whole group (IN-C3), and that issues should be discussed and solved collaboratively (IN-C2). Hence, they regarded the quality of the common work, i.e., they showed increasing eagerness to improve on each other's contributions and correct their classmates' mistakes without waiting for the teacher to do it (IN-C2, INC3). At the end of the learning activities, students positively valued collaboration 
processes: "the most interesting aspect of this activity was working in a team" (FG-C1). As a teacher puts it,

at first it was challenging for students to work as a team towards the same goal. But then they discovered that, all together as a group, they have the ability to overcome obstacles; they learnt that success depends on the group, and could feel the satisfaction to overcome what initially appeared to be unknown and difficult. (IN-C2)

\section{b. Learner-centred}

In the four cases, using wikis allowed teachers to match their pedagogical objectives, content, and materials with student specificities, i.e., age, level of knowledge, and sociocultural identity (EE-C1, EE-C2, EE-C3, EE-C4). For example, teachers in $\mathrm{C} 1$ could address the curricular objectives of four different disciplines through one shared scenario that appeared to perfectly match their students' profile (IN-C1, EE-C1). In C2, the wiki activities involved students creating their own educational content; these matched their learning specificities and, as resources, can eventually be reused with future students (IN-C2). The teacher could address his or her pedagogical objectives "in an innovative manner" (IN-C2) in the context of activities which "fully adapt to the level of students and address different concepts of the discipline" (EE-C2). In C4, the teacher conducted successful writing activities adapted to suit seven-year-old students (IN-C4, EE-C4). Indeed, wiki affordances allowed students to write, illustrate, and share events from their daily lives. In the teacher's words, "It is challenging to involve kids of this age in online writing. For the first time, I could do it, through personalized activities related to their lives and interests: songs, hobbies, and daily activities".

Wikis proved to support learning scenarios that called for learners' interest. Teachers reported students' engagement and motivation in working collaboratively and selfmanaging the learning activities (IN-C1, IN-C2, IN-C3, IN-C4). Students in C1 positively valued their learning experience: "we really enjoyed working together, and we felt free to work in the way we wanted" (FG-C1). Furthermore, the scenario directly connected to their interests (e.g., music, literature, daily issues) (EE-C1). Teachers reported that students who were normally passive showed a high level of motivation (IN-C1). In C4, the teacher expressed her students' engagement:

they became enthusiastic and thrilled when writing for an audience and reading their classmates' contributions; they asked for a new wiki activity every week. So I had students happy and motivated towards me as a teacher, towards using the Internet, and towards learning. (IN-C4)

In all cases, students engaged in group projects which encouraged their active role in learning. For adult learners (C3), self-learning processes took place smoothly, meaning that they naturally took the ownership of activities, autonomously organizing tasks, actively writing in the wiki, publishing visual elements, and posting comments (INC3). In contrast, secondary school students initially required "a lot of guidance" (IN-

C2) to carry out wiki activities, constantly needing their teachers' help to write and format entries and to solve technical doubts about HTML language. Progressively, 
teachers "stepped back" (IN-C2) and took the role of "observers" in the classroom: "we encouraged students to inquire, experiment, solve emerging problems together, and decide on the best way of organizing work" (IN-C1). However, teachers did provide "resources and support" when needed (IN-C1). Benefiting from their teachers' trust, "students progressively gained autonomy and learnt how to self-regulate" to meet the emerging needs of the activities (IN-C2). As a result, they took ownership of the learning process, distributing roles among themselves, searching for resources, selfevaluating their work, finding adequate solutions, and crafting their own content (IN$\mathrm{C} 1, \mathrm{IN}-\mathrm{C} 2$ ). As a student puts it: "in contrast to regular classroom activities, we are free and autonomous; we decide, all together, how to organize our work" (FG-C1). Teachers were positively surprised by the outcomes of their students' project, which were more "personal and crafted" than those produced during regular evaluation activities (IN-C1). In the case of the younger students (C4), the teacher used a wiki environment to help seven-year-olds engage in self-managed writing activities: the children wrote in the wiki platform by themselves, from home, with the teacher reviewing their work and explaining how to solve the technical problems they might encounter ( $\mathrm{IN}-\mathrm{C} 4)$.

The characteristics of wiki environments (especially content development tracking and version management) allowed teachers and students to focus on the learning process rather than on the outcome. Indeed, they constantly reflected on the learning path during the wiki activities. In $\mathrm{C} 1, \mathrm{C} 2$ and $\mathrm{C} 4$, students continuously "reviewed and evaluated at each other's contributions" (IN-C1) with regards to their objectives, "negotiated content, reflected together on how to improve sentences and correct mistakes" (IN-C3), or "made decisions to find the most adequate solutions" (IN-C2). In addition, wiki features allowed teachers to apply innovative assessment methodologies: besides using traditional strategies which look at the learning outcomes (e.g., qualitative analysis of content in the wiki, writing and oral exams, independent projects), teachers applied new ones which focus on processes: using tracking functionalities, they examined students' participation in order to look at their way of collaborating, elaborating and negotiating content (C1, C2 and C3). As explained by a teacher, "I observed my students' behaviours in the classroom; besides, I looked at their individual, collaborative and reflective processes as they were elaborating content in the wiki" (IN-C3). Furthermore, teachers could involve students in the assessment process using self-evaluation grids $(\mathrm{C} 1, \mathrm{C} 3, \mathrm{C} 4)$ and peerevaluations $(\mathrm{C} 1, \mathrm{C} 3)$. In this manner, students reflected on their mistakes, competences, and on the way to improve them (EE-C3). As one teacher observed,

wikis highlighted the trajectory of learning and collaboration, and encouraged students to reflect on their own way of working; we felt that working with these flexible assessment strategies was fairer than working with traditional evaluation ones (IN-C1).

\section{c. Knowledge connection}

The open and inclusive character of wiki environments allowed for connecting learning to real life situations, which made it easier for students to relate to the educational activities. In $\mathrm{C} 1$, students could conduct a varied set of practical activities, including preparing a travel itinerary and writing a diplomatic letter. Furthermore, the 
scenario exploited cultural references from their daily lives (e.g., songs and films), which helped them to find relevance. The expert pointed out that "the proposed activities are realistic and adequate, as they pose problems that students will have to face in their daily life" (EE-C1). In C4, wiki affordances allowed students to write, illustrate, and share events from their daily lives.

Given their flexibility, wikis facilitated the interrelation within and among different areas of knowledge. In $\mathrm{C} 1$, teachers managed to "integrate cross-curricular content in a meaningful scenario" (EE-C1), addressing Spanish and English language learning, visual arts and social sciences: "we attained the objectives of our respective disciplines and discovered a methodology for working in collaboration" (IN-C1); and students could bridge different disciplines by seeing the relationships between them, and also work in three languages (Spanish, Catalan and English). In C4, the scenario promoted not only language learning, but the improvement of social, organizational, and technological skills (EE-C4).

Some wiki activities consisted in searching for, analysing, summarizing, and publishing information on specific topics $(\mathrm{C} 1, \mathrm{C} 2)$. Identifying and locating content online appeared to be easy tasks for students, who were used to doing this on a regular basis, both at school and in personal contexts (IN-C2). On the other hand, they found processing information more of a challenge. Students learnt the importance of analysing content ("examining the source and its level of trust, as well as contrasting different sources", IN-C2), evaluating them "according to their relevance to particular objectives" (IN-C1), and also "appropriating, summarizing, and then reformulating them [the content] in their own words" (IN-C2). This process helped students to critically approach different viewpoints and place knowledge in a wider context.

Wikis' flexible features allowed students to combine text, HTML code, videos, and pictures. As a result, "they expressed themselves using different media, in the context of an integrated project" (IN-C2), meaning that they learnt to embed images $(\mathrm{C} 1, \mathrm{C} 2$, $\mathrm{C} 3, \mathrm{C} 4)$ and the itineraries of maps $(\mathrm{C} 1)$ into a wiki page, create links between pages $(\mathrm{C} 1, \mathrm{C} 2, \mathrm{C} 3)$, and write HTML code (C2) "while learning about different topics from the studied disciplines" (IN-C1).

Finally, wikis appeared to raise students' awareness about content and authors' rights, prompting them to consider the importance of citing the sources of the information used (IN-C1, IN-C2). They also started to use and correctly reference free-foruse resources. As one teacher observed, "even if nobody would report them, they learnt the importance of using information correctly" (IN-C2).

\section{d. Open-ended ethos}

Like other educational technologies, wikis constituted a new learning environment for participating teachers and students. Teachers in $\mathrm{C} 1, \mathrm{C} 2$, and $\mathrm{C} 4$ reported some "uncertainty" while teaching with them: as mentioned earlier, they encountered doubts about technical aspects and teaching strategies. In response to this challenge, teachers decided that "the solution was to accept uncertainty" (IN-C1) and use it as a learning factor: "together, we [teachers and students] explored and progressively discovered the wiki functionalities, and the best way of managing the classroom and solve difficulties" (IN-C4). 
In this context of uncertainty, classroom dynamics shifted, especially in the secondary school classes: "instead of giving students solutions, we provided the class with time and space for exploration; we encouraged class members to freely interact, investigate, and look for and try out solutions, in an unstructured manner" (IN-C1). As one teacher said, "I encouraged my students to search for tutorials on HTML and Mediawiki, ${ }^{5}$ to explore how wikipedians make their contributions" (IN-C2).

As observed above, teachers and students did not initially feel confident when working with wikis. Besides encountering technical and methodological doubts (C1, $\mathrm{C} 2, \mathrm{C} 4$ ), students sometimes felt unsure when writing on wikis: they were aware that their teachers and classmates would know what they were writing and when. As a result, they felt constantly evaluated and were reluctant to show draft work (IN-C1). As the study continued, however, teachers and students quickly began to feel safer and could regard "risk taking and failure" (IN-C4) as essential to finding adequate solutions and solving obstacles. As one teacher observed, "the answer was to dare and jump into the water" (IN-C1), and another commented that "the key was to try out and try out again" (IN-C2). Students understood the positive value of elaborating their ideas on the wiki, making mistakes, communicating with their classmates, correcting and improving their work in an open and progressive manner (IN-C1, FG-C1). Especially in $\mathrm{C} 3$, students became aware that writing in a foreign language is an iterative process that "involves making mistakes" (IN-C3). As the expert puts it, "wikis' collaborative editing and commenting features proved to naturally support this process, allowing students to identify their mistakes, reflect, rewrite and improve" (EE-C3).

\section{Discussion}

The results presented above identified four creative pedagogies which appeared as the most prominent in our study in the context of wiki-based learning; each of them is characterized by different components.

First, the inherent functionalities of wiki environments (collaborative edition, discussion, content development tracking, and version management) proved to foster synergistic collaboration: besides expressing, dialoguing, sharing information, and cooperating (Craft 2005; Hadjerrouit 2012), we found that students in all four cases became involved in rich collaborative practices based on joint problem solving and collective decision making. In this context, democratic classroom practices took place, where students contributed in an equal manner to the completion of their assignments and respected each other's perspectives towards a shared responsibility and group objective.

Second, wikis fostered learner-centred teaching practices: in all four classes, teachers could match curricular objectives with students' profiles and interests, thus making learning relevant and calling for their engagement (Frossard et al. 2015). In addition, teachers' classroom role changed, so that where they had previously adopted a central leading role, they gradually became observers and moderators, encouraging students' ownership, autonomy, and problem solving (Cremin and Barnes 2014). Beyond this, we found that ownership was developed collectively, i.e., students

\footnotetext{
${ }^{5}$ www.mediawiki.org
} 
progressively gained trust and autonomy as part of a group by organizing together their own system of rules. Additionally, wiki transparency (provided by content development tracking and version management features) allowed teachers to value learning processes above outcomes, and also allowed students to increase their metacognitive abilities by critically reflecting on their learning trajectory.

Third, the flexibility of wiki environments proved to support educational activities that facilitate knowledge connections, i.e., linking content to real life situations and bridging different domains and disciplines (Frossard et al. 2015). Students could also critically apprehend content by contrasting different sources of information, media, and tools (Cremin and Barnes 2014). In the context of wikis, such connections proved to help students reinforce information literacy skills: how to manage information, evaluate it critically, and use it accurately for the task at hand, as well as to understand the ethical and legal issues surrounding the use and publication of information in the wiki.

Finally, the adoption of wiki approaches promoted an open-ended ethos in the classroom, by providing space for uncertainty, exploration, and spontaneity (Cremin and Barnes 2014). Furthermore, wiki reinforced the idea of safe classroom

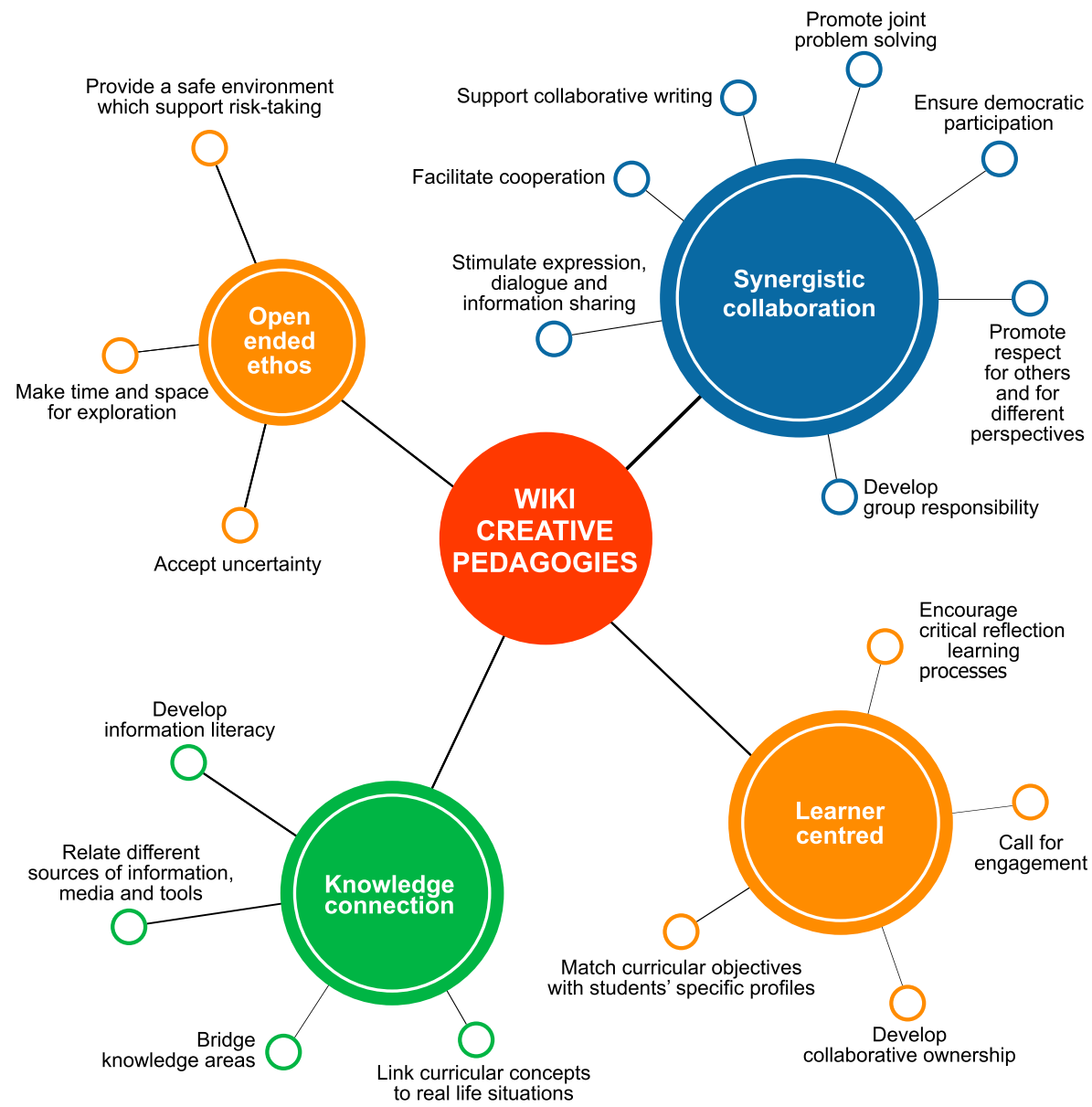

Fig. 1 Map of wiki key creative pedagogies and their characteristic components 
environments (Sawyer 2012) in which students can elaborate, correct, and improve their ideas from drafting to proofreading, as well as take risks by engaging in trial and error practices and using failure as a learning factor.

In the light of the theoretical background, and following the results of the comparative analysis, Fig. 1 maps the key creative pedagogies that emerged in the design and application of wiki-based learning scenarios. Each creative pedagogy (represented by a coloured circle) is characterized by different components (represented by spires). The weight of each creative pedagogy is represented by the size of its circle, i.e., it relates to its number of characteristic components, as reflected in the comparative analysis performed in Section 4.

Results showed that the components of creative pedagogies, as represented in Fig. 1, helped to overcome the challenges encountered while teaching and learning with wikis. The initial technical difficulties (Hadjerrouit 2012) and methodological concerns were solved progressively as teachers and students accepted uncertainty, making time and space for exploration and joint problem solving as part of the learning process. Students' initial lack of autonomy gave way to collaborative ownership as teachers encouraged them to experiment and solve problems together in a trusting manner. Students' fear of exposing draft work (Su and Beaumont 2010) faded when they started to consider wiki as a safe environment in which trial and error is part of the learning process. Students' reluctance to collective knowledge production and authorship (Ricaurte-Quijano and Carli-Álvarez 2016), as well as their tendency to engage in cooperative rather than collaborative processes (Hadjerrouit 2012; Judd et al. 2010), dissolved as they realized the potential of collaboration to solve problems while developing a sense of group responsibility.

\section{Conclusions}

Our study aimed to investigate the potential of wiki-based learning for fostering creativity in teaching and learning settings. We adopted an innovative approach whereby teachers designed their own wiki-based learning scenarios and applied them with students. Using a multiple case study, we explored the potential of this approach for promoting creativity. Our results map the creative pedagogies that appeared as the most prominent in the context of wiki-based learning, together with their characteristic components. Namely, the emerging creative pedagogies are synergistic collaboration, learner-centred, knowledge connection, and open-ended ethos. We consider that this map of creative pedagogies can be applied in further research to different educational contexts, although it may vary according to the specificities of the methodology and the pedagogical affordances of the technology used. The study addresses a small number of disciplines and cases; furthermore, the results reflect the educational system of one country. A wider study would allow for increasing the transferability of results.

In this research, wiki-based learning appears to strongly relate to little-c creativity (Craft 2001; Beghetto and Kaufman 2014), in the sense that wiki affordances supported learners' subjective processes rather than being product-oriented. Indeed, students had the opportunity to constantly engage in metacognitive practices by reflecting on learning paths, evaluating each other's contributions, negotiating content, making consensual decisions, and following up content development. By engaging in open 
learning mediated by wiki environments, teachers and students could experience the social process of knowledge production, as well as reflect on the new codes and possibilities offered by the participative digital culture.

This study contributes to bridging the gap in education studies between two bodies of research: one on creativity, and the other on wikis and open learning. Finally, we provide educational practitioners with concrete examples of the application of creative pedagogies, thus contributing to a greater understanding of the phenomenon of creativity as applied to learning.

Acknowledgements This work was supported by the European Commission, WikiSkills project [Lifelong Learning Programme, contract number 519291-LLP-1-2011-1-CH-KA3-KA3MP]. This publication reflects the views only of the author, and the Commission cannot be held responsible for any use which may be made of the information contained therein.

\section{Appendix: Interview guide}

1. What motivated you to design the wiki-based scenario?

2. What aspects did you take into consideration while designing your scenario?

3. How did the wiki functionalities support teaching and learning practices?

4. How did you organize educational activities around the wiki?

5. How did you manage students' work and interactions?

6. What evaluation strategies did you use to assess students' learning?

7. To what extend did you reach your curricular objectives through the design and use of the wiki-based learning scenario?

8. What skills did students develop while working with wikis?

9. How did the use of wiki support or hinder the following teaching and learning aspects?

a. Linking different disciplines and content

b. Connecting to students' interests

c. Developing opportunities for students' collaboration

d. Allowing for students' autonomy

e. Offering space for investigation and discovery

10. What challenges did you encounter while designing and applying your wikibased learning scenario?

11. What solutions did you apply to overcome those challenges?

12. Do you plan to further design and / or use wikis in your educational contexts?

\section{References}

Amabile, T. M. (1996). Creativity in context. Boulder: Westview.

Beghetto, R. A. (2010). Creativity in the classroom. In J. C. Kaufman \& R. J. Sternberg (Eds.), The Cambridge handbook of creativity (pp. 447-463). Cambridge: Cambridge University Press.

Beghetto, R. A., \& Kaufman, J. C. (2014). Classroom contexts for creativity. High Ability Studies. https://doi.org/10.1080/13598139.2014.905247. 
Biasutti, M., \& El-Deghaidy, H. (2012). Using wiki in teacher education: Impact on knowledge management processes and student satisfaction. Computers \& Education. https://doi.org/10.1016 /j.compedu.2012.04.009.

Cole, M. (2009). Using wiki technology to support student engagement: lessons from the trenches. Computers \& Education, 52(1), 141-146.

Craft, A. (2001). Little c creativity. In A. Craft, R. Jeffrey, \& M. Leibling (Eds.), Creativity in education (pp. 45-61). London: Continuum.

Craft, A. (2005). Creativity in schools: tensions and dilemmas. London: Routledge.

Craft, A., Cremin, T., Hay, P., \& Clack, J. (2014a). Creative primary schools: developing and maintaining pedagogy for creativity. Ethnography and Education. https://doi.org/10.1080/17457823.2013.828474.

Craft, A., Hall, E., \& Costello, R. (2014b). Passion: Engine of creative teaching in an English university? Thinking Skills and Creativity. https://doi.org/10.1016/j.tsc.2014.03.003.

Cremin, T., \& Barnes, J. (2014). Creativity and creative teaching and learning. In T. Cremin \& J. Arthur (Eds.), Learning to teach in the primary school (3rd ed., pp. 467-481). Abingdon: Routledge.

Creswell, J. W. (2012). Educational research: planning, conducting, and evaluating quantitative and qualitative research (4th ed.). Boston: Pearson.

Davies, D., Jindal-Snape, D., Collier, C., Digby, R., Hay, P., \& Howe, A. (2013). Creative environments for learning in schools. Thinking Skills and Creativity. https://doi.org/10.1016/j.tsc.2012.07.004.

Duffy, P., \& Bruns, A. (2006). The use of blogs, wikis and RSS in education: a conversation of possibilities. Proceedings of the Online Learning and Teaching Conference 2006, Brisbane, 2006, pp. 31-38.

Frossard, F., Barajas, M., \& Trifonova, A. (2015). Teachers designing learning games: impact on creativity. In J. C. Kaufman \& G. Green (Eds.), Video games and creativity. Explorations in creativity research (pp. 160-180). New York: Academic Press.

Hadjerrouit, S. (2012). Investigating technical and pedagogical usability issues of collaborative learning with wikis. Informatics in Education: An International Journal, 11(1), 45-64.

Jeffrey, B., \& Craft, A. (2004). Teaching creatively and teaching for creativity: distinctions and relationships. Educational Studies. https://doi.org/10.1080/0305569032000159750.

Judd, T., Kennedy, G., \& Cropper, S. (2010). Using wikis for collaborative learning: assessing collaboration through contribution. Australasian Journal of Educational Technology. https://doi.org/10.14742/ajet.1079.

Kear, K., Donelan, H., \& Williams, J. (2014). Using wikis for online group projects: student and tutor perspectives. International Review of Research in Open and Distance Learning, 15(4), 70-90.

Leuf, B., \& Cunningham, W. (2001). The wiki way: quick collaboration on the web. Boston: Addison Wesley.

Lin, Y. S. (2011). Fostering creativity through education: conceptual framework of creative pedagogy. Creative Education. https://doi.org/10.4236/ce.2011.23021.

Lin, Y. S. (2014). A third space for dialogues on creative pedagogy: where hybridity becomes possible. Thinking Skills and Creativity. https://doi.org/10.1016/j.tsc.2014.03.001.

NACCCE. (1999). All our futures: creativity, culture and education. London: Department for Education and Employment.

$\mathrm{Ng}, \mathrm{M}$. W. (2016). Fostering pre-service teachers' self-regulated learning through self-and peer assessment of wiki projects. Computers \& Education. https://doi.org/10.1016/j.compedu.2016.03.015.

Parker, K., \& Chao, J. (2007). Wiki as a teaching tool. Interdisciplinary Journal of e-learning and Learning Objects, 3(1), 57-72.

Pifarré, M., \& Kleine-Staarman, J. (2011). Wiki-supported collaborative learning in primary education: how a dialogic space is created for thinking together. International Journal of Computer-Supported Collaborative Learning. https://doi.org/10.1007/s11412-011-9116-x.

Pifarré, M., Martí, L., \& Guijosa, A. (2014). Collaborative creativity processes in a wiki: study in secondary education. In D.G. Sampson, J.M. Spector, D. Ifenthaler, \& P. Isaias (Eds). 11th International Conference on Cognition and Exploratory Learning in Digital Age (CELDA 2014), Porto, 2014.

Popescu, E. (2014). Using wikis to support project-based learning: a case study. Proceedings of the IEEE 14th international conference on advanced learning technologies, Athens, 2014, pp. 305309. https://doi.org/10.1109/ICALT.2014.94.

Ricaurte-Quijano, P., \& Carli-Álvarez, A. (2016). The wiki learning project: wikipedia as an open learning environment. Comunicar Journal. https://doi.org/10.3916/C49-2016-06.

Sawyer, R. K. (2012). Explaining creativity: the science of human innovation (2nd edn.). New York: Oxford University Press.

Su, F., \& Beaumont, C. (2010). Evaluating the use of a wiki for collaborative learning. Innovations in Education and Teaching International. https://doi.org/10.1080/14703297.2010.518428. 